obtained during the menstrual cycle, ${ }^{3}$ pregnancy, ${ }^{4}$ and in cases of amenorrhoea with normal $\mathrm{LH}$ and FSH responses to synthetic gonadotrophin releasing hormone and with no pituitary tumour, ${ }^{3}$ indicating that prolactin secretion is stimulated by endogenous oestrogens. Exogenous oestrogens also stimulate prolactin secretion in women. ${ }^{5}$ Thus oestrogens are an important factor in the control of prolactin secretion in humans. The decrease of serum prolactin levels with age in women and their rising trend with age in men is of practical value in interpreting the results of prolactin assays.

We thank Mrs Josiane Delogne-Desnoeck, Viviane Joostens-Defleur, Arlette Michaux-Duchene, Henriette Preszow-Luftman, and Mr F Van Meenen for technical assistance, and the National Institute of Arthritis, Metabolism and Digestive Diseases, USA, for human pituitary prolactin (HPR VLS-1 and VLS-2). This work was supported by research grants to Professor P O Hubinont from the Fonds de la Recherche Scientifique Medicale of Belgium and from the Ford Foundation.

1 Badawi, M, et al, in Radioimmunoassay and Related Procedures in Clinical Medicine and Research, $\mathrm{p} 411$. Vienna, International Atomic Energy Agency, 1974.

2 Longcope, C, American fournal of Obstetrics and Gynecology, 1971, 111, 778.

${ }^{3}$ Robyn, C, et al, in Human Prolactin, ed J L Pasteels and C Robyn, p 167. Amsterdam, Excerpta Medica, 1973.

${ }^{4}$ L'Hermite, M, and Robyn, C, Annale d'Endocrinologie (Paris), 1972, 33, 357.

5 Vekemans, M, and Robyn, C, fournal of Clinical Endocrinology, 1975, 40, 886.

Human Reproduction Research Unit, Hôpital Saint-Pierre, Université Libre de Bruxelles, 1000-Bruxelles, Belgium

$M$ VEKEMANS, MD, aspirant, Fonds National Belge de la Recherche Scientifique

C ROBYN, MD, lecturer

\section{Ischaemic brain damage of cerebral perfusion failure type after treatment of severe hypertension}

Autoregulation of the cerebral circulation is a homoeostatic mechanism whereby cerebral blood flow (CBF) is kept within normal limits over a wide range of systemic arterial pressure. ${ }^{1}$ In hypertensive patients autoregulation is adapted to a high blood pressure so that symptoms of brain ischaemia may develop during antihypertensive treatment at a blood pressure that is 'well tolerated by normotensive people. ${ }^{2}$

\section{Case reports}

Case 1-A 60-year-old woman with a BP of $240 / 140 \mathrm{~mm} \mathrm{Hg}$, and bilateral retinal haemorrhages and exudates but no papilloedema, was given in addition to her usual treatment of methyldopa, $250 \mathrm{mg}$ four times daily, an oral dose of $25 \mathrm{mg}$ bethanidine. Two hours later her BP was $120 / 85 \mathrm{~mm} \mathrm{Hg}$ and she was deeply unconscious. A few hours later she was lucid and by next morning had returned to her former mental state. There were no focal neurological signs. Bilateral angiography gave normal findings. The patient died 12 days after the hypotensive episode.

Case 2-A 35-year-old woman with a BP of $240 / 170 \mathrm{~mm} \mathrm{Hg}$, bilateral retinal haemorrhages, and papilloedema, and who had not been receiving treatment for hypertension, was given $2.5 \mathrm{mg}$ pentolinium intravenously. Immediately after the injection, the BP fell briefly to an unrecordable level; 15 mintes later the BP was $120 / 100 \mathrm{~mm} \mathrm{Hg}$ and within 24 hours it was $200 / 140 \mathrm{~mm} \mathrm{Hg}$. She remained unconscious for three days with bilateral pyramidal tract signs and, although her conscious level improved thereafter, her mental state remained grossly impaired until she died six months later. Necropsy showed left ventricular hypertrophy in both cases. In case 1 there was unilateral atheromatous stenosis of the renal artery, and in case 2 the kidneys were small and showed microscopic features of progressive systemic sclerosis. Evidence of "malignant" hypertension was seen in both cases. The brains were fixed intact before dissection. In each there was ischaemic damage in the boundary zones between the major arterial territories (fig) and variable damage in deeper structures. Reactive changes were consistent with the damage having occurred at the time of the recorded hypotensive episodes. Though moderately atheromatous, all the major intracranial and extracranial arteries were patent.
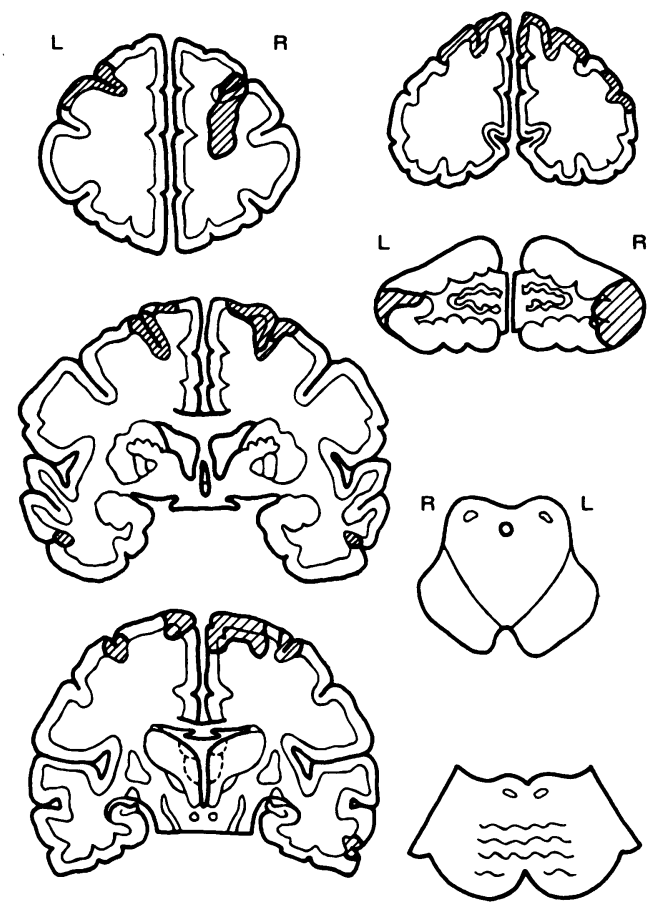

政

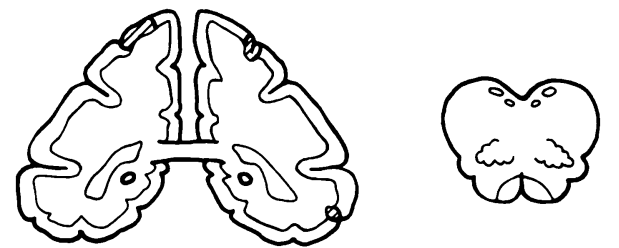

Case 2. Distribution of infarction in the boundary zones between the major arterial territories of the cerebral and cerebellar hemispheres (hatched).

\section{Discussion}

The distribution of ischaemic brain damage in these two patients is similar to the commonest pattern found with a precipitate reduction in CBF resulting from a severe episode of hypotension both in man $^{3}$ and in primates. ${ }^{4}$ There seems little doubt from the clinicopathological correlates that the boundary zone infarction in these cases occurred because of the hypotensive episode precipitated by the antihypertensive drugs. In particular, in case 1 the lowest BP recorded was $120 / 85 \mathrm{~mm} \mathrm{Hg}$ - a level well above the lower limit of effective autoregulation in a normotensive person. ${ }^{5}$ Hence probably because of impaired autoregulation this patient sustained a critical reduction in cerebral blood flow at a level of BP that under normal circumstances would not have given rise to concern.

Although the advantages of reducing the $\mathrm{BP}$ in patients with severe hypertension usually outweigh the dangers of excessive lowering of the BP, the two cases reported here show a potential hazard of lowering it too rapidly in hypertensive patients and emphasise the importance of titrating the dose of hypotensive agent against the level of the blood pressure.

I would like to thank Dr J D Aitchison, Stirling Royal Infirmary, and Dr J S Robertson, MRC Blood Pressure Unit, Glasgow Western Infirmary, for permission to quote from their records.

1 Lassen, N A, Physiological Reviews, 1959, 39, 183.

2 Strandgaard, S, et al, British Medical fournal, 1973, 1, 507.

3 Adams, J H, et al, Brain, 1966, 89, 235.

4 Brierley, J B, et al, Brain Research, 1969, 13, 68

5 Olesen, J, Archives of Neurology, 1973, 28, 143.

University Department of Neuropathology, Institute of Neurological Sciences, Southern General Hospital, Glasgow G51 4TF, Scotland D I GRAHAM, MB, MRCPATH, senior lecturer in neuropathology 